\title{
The Effectiveness of Life Skills Training on the Social Skills of Deaf Students
}

\author{
Mohammad Ashori* \\ Assistant Professor, Department of Psychology and Education of Children with Special Needs, Faculty of Education and \\ Psychology, University of Isfahan, Isfahan, Iran
}

*Corresponding author: Mohammad Ashori, Assistant Professor, Department of Psychology and Education of Children with Special

Needs, Faculty of Education and Psychology, University of Isfahan, Isfahan, Iran

\section{ARTICLE INFO}

Received: 慧 June 26, 2019

Published: 幽 July 03, 2019

Citation: Mohammad Ashori. The Effectiveness of Life Skills Training on the Social Skills of Deaf Students. Biomed J Sci \& Tech Res 19(3)-2019. BJSTR. MS.ID.003291.

Keywords: Life skills; Social skills; Deaf students

\begin{abstract}
The aim of this research was to investigate the effectiveness of life skills training on the social skills of deaf students. The present research was used the experimental method with pretest, posttest design and a control group. The participants were 24 deaf students, with sensory-neural hearing impairment in the range of 50 to 80 decibels. They were selected from two schools for the deaf in Tehran Province using a random sampling method. Subjects were randomly divided into an experimental group and a control group, each consisting of 12 students. The experimental group received life skills training within 9 sessions, while the control group did not. Social skills rating scale was used for measuring their social skills. The obtained data was analyzed by MANCOVA. The results showed that life skills training had a significant effect on the social skills and subscales (cooperation, assertiveness and self-control) in the experimental group $(\mathrm{P}<0.0001)$. Life skills training can improve the social skills of deaf students. Therefore, training of life skills has a crucial role in improving the social skills of these students
\end{abstract}

\section{Introduction}

Deafness is a heterogeneous condition with far-reaching effects on emotional, social, and cognitive development [1,2]. Hearing loss affects $15 \%$ to $26 \%$ of the world's population, with the highest prevalence in low income countries [3-5]. About, 7 per 10.000 people in the overall population are deaf [6,7]. Hearing loss is a prevalent and disabling chronic condition that can impair communication, social relationships and social skills [8]. Hearing is one of the essential learning tools for interaction with others, acquisition of language skills, and prerequisite for development of each child [9]. Deafness can lead to developmental delay and lifelong difficulties. Deaf individuals would have difficulties in social skills [10]. Social skills deficit is one of the main factors which can lead to behavior problems, academic failure, isolation and rejection in deaf students [11].

Table 1: The content of life skill program sessions.
Social skills can be defined as skills that allow each child to interact with others successfully. Sometimes individuals with a disability have behaviors that are unacceptable in social relationships [12]. The inappropriate social skills can be a characteristic of their disability. Children may lack a specific social skill, may apply an inappropriate social skill to a specific situation, or may not be aware that a specific situation calls for a specific skill set [13]. Social skills and life skills program for deaf children can be divided into the areas of academic and non-academic programs. Social skills training would be considered non-academic program [14]. Usually, the emphasis on training with respect to social behaviors has been hiding by academic program. By providing social skills training, deaf children can learn to get along with others and adapt to various social conditions [15] (Table 1).

\begin{tabular}{|c|c|c|}
\hline Sessions & Skills & Context of program in each session \\
\hline 1 & $\ldots \ldots \ldots .$. & Familiarization with life skill program and goals \\
\hline 2 & Self-development & Identify of positive characteristics of the students, Diagnosis of between misunderstanding and make a mistake \\
\hline 3 & & Identify of desirable or not characteristics, Development and change perception in the span life \\
\hline
\end{tabular}




\begin{tabular}{|c|c|c|}
\hline 4 & Emotions-development & $\begin{array}{l}\text { Rejected perception and loneliness on others, Effective methods of coping with rejection and loneliness, Role of } \\
\text { self in sensation assertion }\end{array}$ \\
\hline 5 & & $\begin{array}{c}\text { Identify of unfavorable emotions, Effective methods of adjustment with emotions, Tolerance of rejection and } \\
\text { loneliness }\end{array}$ \\
\hline 6 & Social development & Cooperation and collaboration, Effective interpersonal interactions, Decision-making of appropriate \\
\hline 7 & & $\begin{array}{l}\text { Effective skills in the conflict management, identify of rejection and loneliness causes, External word thinking of } \\
\text { other perspective }\end{array}$ \\
\hline 8 & Cognitive development & $\begin{array}{l}\text { Selections and diagnosis of each one important, Separation of reasonable belief, Attention to positive and } \\
\text { negative outcome of decisions }\end{array}$ \\
\hline 9 & & Coping with stress and emotions, Review of programs \\
\hline
\end{tabular}

Some studies have proven that inappropriate social skills are an important element contributing to the failure of deaf individuals in community placements [8]. In addition, social learning theory by Albert Bandura can be applied to the development of social skills in deaf children. Social learning emphasizes the importance of observation and subsequent modeling of attitudes, behaviors, and emotional reactions of others [11]. Bandura's theory is also based on the premise that social relationships play a main role in the cognitive development of individuals [16].

The first serious discussions and analyses of life skills emerged by Botvin in 1979. This approach aims to assist young people to regain control over their behavior while taking informed decisions that can lead to positive behaviors and values [14]. In addition, it can provide opportunities for students to practice interpersonal skills by using interactive education and learning methods. Life skills training helps students to increase their social and personal development [13]. Life skills training program to prevent substance abuse for middle and junior high school students. Such life skills training programs have demonstrated immediate and dramatic positive effects on children, adolescent and adults [15]. Life skills training includes communication, self-awareness, empathy, decision making, interpersonal relationship, creative thinking, problem-solving, critical thinking, coping with stress, and coping with emotions skills. Life skills program effectively teach skills that help to enhance personal and social competencies and decrease risky behaviors [12].

The finding research of Turner, Mc Donald and Somerset showed that there was significant relationship among life skills, mathematical reasoning and critical thinking. Study result of Korinek \& Popp indicated that verbal and non-verbal behavior affected on peer's interactions and social consequence of students. Finding research of Movallali, Ashori, Jalil-Abkenar and Salehy showed that [8] life skills training had positive and significant effect on the cooperation, assertion, self-control and social skills of hearing-impaired students. Mahvashevernosfaderani, Adibsereshki \& Movallali showed that life skills training had significant effect on the cooperation, assertion, self-control and social skills in the hearing loss students. Also, research result of Kazemi, Momeni \& Kiamarsi indicated that life skills training increased behavioral skills of students with dyscalculia.
Most children learn social skills from interaction with other children, friends, and family members, while deaf students did not and need to learn social behaviors and skills directly. This may include the use of a specific program and the use of individualized methods. So, it is necessary to pay attention to the life skills training for deaf students. Therefore, the aim of this research was to investigate the effectiveness of life skills training on the social skills of deaf students.

\section{Materials and Methods}

This is an experimental study with pretest and posttest design and a control group. Sample includes 24 deaf students between 12 and 14 years of age who had enrolled in public schools in Tehran Province during the academic year 2017. Participants were selected by random sampling method. From the list of schools, two schools were randomly selected. Participants were selected randomly from these two schools and were divided into two groups randomly (experimental and control group), each of which consisted of 12 deaf students. The inclusion criteria were being diagnosed prelingually deaf with sensory-neural hearing loss in both ears, being hearing loss in the range of 50 to 80 Decibels $(\mathrm{dB})$, being hearing aids in both ears, IQ between 90-100, aged 12-14 years old and living with parent. Participants would be excluded from research if there was any symptom of neurodevelopmental disability or significant health problems except for deafness. Also, those who were currently receive similar training program were excluded from the study.

The Social Skills Rating Scale-Teacher Form (SSRS-T) was used for assessing of participants. This scale was developed by Frank Gresham and Stephen Elliot in 1990. SSRS-T is a 30-item measure with three subscales (cooperation, assertion, self-control) and 10 items each. A total score can range from 0 to 60 . SSRS-T is rated on a 3-point Likert scale ranging from 0 (never) to 2 (often). Higher scores indicate better social skills and lower scores indicate impairment in social skills. Internal consistencies of SSRS are satisfactory. The internal consistency of SSRS subscales ranged from 0.51 to 0.91 , with a mean internal consistency of 0.75 (21). Furthermore, Shahim [22] has found high alpha coefficients (0.92) for the teacher versions. The internal validities of the cooperation, assertion, and self-control subscales have been calculated by Cron $\neg$ bach's alpha and were $0.79,0.63$, and 0.88 , respectively. 
The importance of this study was described for participants and mothers. Mothers of participants provided their informed consent. Assigning the participants into experimental and control group was carried out randomly. In fact, name of participants was written on paper. So, names were put on glass container for lottery. To assess social skills of experimental and control group, SSRS-T was used as pre-test. In the later stage, experimental group participated in 9 sessions in the life skill training program (twice

Table 2: Descriptive statistics for social skills in study groups. a week; each lasting for 50 minutes), while control group did not receive this program. Life skill training program has been applied in the several research studies. This program was designed based on Movallali and et al. [8] reported in Table 2. In the final stage of the research, each of the two groups was assessed by SSRS-T as posttest. The data were analyzed by multivariate analysis of covariance (version 24, SPSS Inc., Chicago, IL).

\begin{tabular}{|c|c|c|c|c|c|}
\hline \multirow[t]{2}{*}{ Depended variable } & \multirow[t]{2}{*}{ Situation } & \multicolumn{2}{|c|}{ Experimental group } & \multicolumn{2}{|c|}{ Control group } \\
\hline & & Mean & SD & Mean & SD \\
\hline \multirow[t]{2}{*}{ Cooperation } & Pre-test & 8.94 & 1.12 & 8.89 & 1.10 \\
\hline & Post-test & 12.11 & 1.24 & 8.91 & 1.34 \\
\hline \multirow[t]{2}{*}{ Assertion } & Pre-test & 9.27 & 0.99 & 9.16 & 1.07 \\
\hline & Post-test & 13.45 & 1.02 & 9.33 & 0.97 \\
\hline \multirow[t]{2}{*}{ Self-control } & Pre-test & 8.74 & 0.96 & 8.81 & 083 \\
\hline & Post-test & 12.03 & 1.27 & 8.95 & 1.01 \\
\hline \multirow[t]{2}{*}{ Social skills } & Pre-test & 26.95 & 2.15 & 26.86 & 2.18 \\
\hline & Post-test & 37.59 & 2.06 & 27.19 & 2.29 \\
\hline
\end{tabular}

\section{Results}

In experimental and control group average ages were 12.93 years and 13.07 and average IQ were 95.64 and 95.59, respectively. The descriptive indexes (Mean scores and standard deviation) of social skills and subscales (cooperation, assertion, self-control) of deaf student in experimental and control group in pretest and posttest are shown in Table 2. The first research question was to investigate the effectiveness of life skills training on the social skills of deaf students. ANCOVA was used because of the presence of one independent variable and one dependent variable and the moderate pre-test effect. After checking and confirmation of the normality of research variables, Leven's test approved variance equality $(P>0.05)$. Therefore, ANCOVA test could be applied, whose results are reported in Table 3.

Table 3: Analysis of covariance summary.

\begin{tabular}{|c|c|c|c|c|c|c|}
\hline Source & SS & df & MS & F & Sig & ๆ2 \\
\hline Pretest & 64.97 & 1 & 64.97 & 25.67 & $0.0001>$ & 0.31 \\
\hline Group & 117.34 & 1 & 117.34 & 46.37 & $0.0001>$ & \\
\hline Error & 53.18 & 21 & 2.53 & & & \\
\hline Total & $261 . .1$ & 23 & & & \\
\hline
\end{tabular}

As can be seen Table 2, the effect of the covariate (pre-test) was significant, $\mathrm{F}(1,21)=25.67, \mathrm{P}<0.0001$, indicating that the pretest and posttest were significantly correlated. Also, the effect of between groups was significant, $\mathrm{F}(1,21)=46.37, \mathrm{P}<0.0001$. In summary, the ANCOVA tells us that the two groups' means were significant difference and the life skill training had a positive and significant effect on the social skills of deaf students. To assess the subscales of social skills (cooperation, assertion, self-control) between experimental and control group was used MANCOVA. After checking and confirmation of the normality of research

Table 4: Multivariate analysis of covariance summary. variables, Box's test approved equality of variance-covariance matrices $(\mathrm{P}>0.05)$. Also, the assumption of variance equality was approved by using Leven's test $(\mathrm{P}>0.05)$. Therefore, MANCOVA test could be applied. The overall score Wilk's lambda was significant, $(F(2,19)=6.11, P<0.001)$, indicating that experimental and control groups had significant difference, at least in one variable. In order to determine differences among scores of cooperation, assertion, self-control between control and experimental groups, MANCOVA test was used, whose results are reported in Table 4 .

\begin{tabular}{|c|c|c|c|c|c|c|c|}
\hline \multirow{2}{*}{ Source } & Depended variable & SS & df & MS & F & Sig & ү2 \\
\hline \multirow{3}{*}{ Pre-test } & Cooperation & 21.14 & 1 & 21.14 & 11.17 & 0.001 & 0.26 \\
\cline { 2 - 8 } & Assertion & 16.37 & 1 & 16.37 & 7.06 & 0.001 & 0.22 \\
\cline { 2 - 8 } & Self-control & 17.42 & 1 & 17.42 & 7.99 & 0.001 & 0.23 \\
\hline
\end{tabular}




\begin{tabular}{|c|c|c|c|c|c|c|}
\hline \multirow{3}{*}{ Group } & Cooperation & 60.22 & 1 & 60.22 & 24.98 & 0.0001 \\
\cline { 2 - 7 } & Assertion & 47.36 & 1 & 47.36 & 19.66 & 0.0001 \\
\cline { 2 - 7 } & Self-control & 50.54 & 1 & 50.54 & 20.53 \\
\hline
\end{tabular}

As can be observed Table 4, there are significant difference among subscales scores of cooperation, assertion and self-control skills between experimental and control group $(\mathrm{P}<0.0001)$. The results of MANCOVA showed that life skills training had significant and positive effect on the cooperation $(\mathrm{F}=24.98, \mathrm{P}<0.0001)$, assertion ( $\mathrm{F}=19.66, \mathrm{P}<0.0001)$ and self-control skills $(\mathrm{F}=20.53, \mathrm{P}<$ 0.0001).

\section{Discussion}

First, this study evaluated the effectiveness of life skills training on the social skills of deaf students into two groups (experimental and control) at the pre-test and post-test. Second, differences between experimental and control group were examined by subscales of social skills (cooperation, assertion \& self-control) at the pretest and posttest. With respect to the first research question, the present study supports the effectiveness of life skills training on the social skills of deaf students. This result was similar with study result of Movallali and et al. [8] that concluded life skills training had a significant and positive effect on the social skills of deaf students. Recent finding was similar with research result of Turner and et al. [17] that concluded there were significant relationship among life skills, mathematical reasoning and critical thinking. Also, was similar with study result of Korinek and Popp [18] that concluded verbal and non-verbal behavior affected on peer's interactions and social consequence of students.

For explanation this result can concluded that although some deaf students are able to pick up positive skills through their everyday interactions with adults and peers, it is important that educators and parents reinforce learning of social skills with direct and indirect training of life skills [19-23]. As a result of this increase in change scores within the experimental group, it can be assumed that over time a life skills training curriculum can have positive effects. Consequently, a functional curriculum supported by academics allows for deaf students to utilize functional skills that enabled them to live and work within their community. Therefore, the curriculum utilized in the education of deaf students must include integrated life skills as well as an academic curriculum. One such vital life skill essential for deaf students to be exposed to was personal or social skills.

Regarding the second research question, the results of present research showed that life skills training had significant and positive effect on the cooperation, assertion and self-control skills. This finding was similar with study result of Movallali and et al. [8] and Mahvashevernosfaderani and et al. [19] that concluded life skills training had significant effect on the cooperation, assertion and self-control skills in the hearing loss students. Also, was similar with study result Kazemi and et al. [20] that concluded life skills training increased behavioral skills of students with dyscalculia.
To explanation this result can concluded that deaf students was the lack of social skills. However, the major content areas were being pushed in legislation and not the functional curriculum that was needed for deaf students. This study addressed whether or not a life skills instruction curriculum positively affects the performance of deaf students on knowledge-based assessment and a social skills rating scale [11]. In other hand, for deaf students, a functional curriculum supported by academics allows them to utilize functional skills that enabled them to live and work within their community. However, the current trend is for students to be exposed to the general education curriculum, preventing students from receiving essential instruction in nonacademic areas such as social skills. The increase in scores of the social skills curriculum indicated that long-term extensive instruction could be beneficial to continue to incorporate necessary functional life skills into the curriculum of deaf students [12]. Finally, the mandate for transitional services is a new change in special education. Transitional services include vocational instruction, postsecondary education, integrated employment, educated in adulthood, independent living, adult services, and community participation. The life skills program might help children to learn and develop the vital skills they will need to be productive and successful upon making the transition from school to community life and work [8].

In conclusion, this study demonstrated that life skills training promoted social skills of deaf students. Life skills training is a multilevel behavioral intervention, based on social learning principles, which aims to prevent and treat behavioral, emotional, and developmental problems in children and adolescents by enhancing their knowledge, skills, and self-concept. However, life skills training can lead to enhancement of relationships and interaction of students, planning for life skills training has particular importance.

Several limitations of the current research should be noted. One major limitation is that this study only examined the effect of life skills training on the social skills in the prelingually deaf children aged 12-14 years old with sensory-neural hearing loss in the range of 50 to 80 decibels. A second limitation is that this study was disregard to the diversity in the hearing condition and socioeconomic status in parents of subjects. A third limitation is that this study was without follow up stage, because of the time limitation, opportunity for follow up stage was not provided. Therefore, these limitations made it difficult to generalize the findings of the study to the other population and clearly this is an area that needs further research.

This study created several recommendations for further study. First, it is recommended that regarded the pre-lingually and postlingually deaf children in different ages with type of hearing loss. Second, regarded the hearing condition and socio-economic status 
in parent of subjects. Third, provided opportunity for follow up stage. Moreover, since social skills multidimensional and complex phenomenon, deaf children require special training program.

\section{References}

1. Lawyer G (2018) Deaf education and deaf culture: Lessons from Latin America. American Annals of the Deaf 162(5): 486-488.

2. Fellinger J, Holzinger D, Sattel H, Laucht M, Goldberg D (2009) Correlates of mental health disorders among children with hearing impairments. Journal of Development Medical Children Neural 5: 635-641.

3. Agrawal Y, Platz EA, Niparko JK (2008) Prevalence of hearing loss and differences by demographic characteristics among US adults: data from the National Health and Nutrition Examination Survey. Arch Intern Med 168: $1522-1530$

4. Zhang F, Underwood G, McGuire K, Liang C, Moore DR, et al. (2019) Frequency change detection and speech perception in cochlear implant users. Hearing Research 379: 12-20.

5. Roy RA (2018) Auditory working memory: A comparison study in adults with normal hearing and mild to moderate hearing loss. Global Journal of Otolaryngology 13(3): 1-14.

6. Bubbico L, Rosano A, Spagnolo A (2007) Prevalence of prelingually deafness in Italy. Acta Otorhinolaryngol Ital 27: 17-21.

7. Hall M, Eigsti IM, Bortfeld H, Lillo-Martin D (2016) Auditory deprivation does not impair executive function, but language deprivation might: Evidence from a parent-report measure in deaf native signing children. Journal of Deaf Studies and Deaf Education 22(1): 1-13.

8. Movallali G, Ashori M, Jalil-Abkenar SS, Salehy Z (2014) Effect of life skills training on social skills of hearing-impaired students. IOSR Journal of Research \& Method in Education (IOSR-JRME) 4(5): 28-34.

9. Caldeira JMA, Goffi-Gomez MVS, Imamura R, Bento RF (2019) Speech recognition of cochlear implant users inside a noisy helicopter environment. Audiology Neuroethology 24(1): 32-37.

10. Cao Z, Gao J, Huang S, Xiang H, Zhang C, et al. (2019) Genetic polymorphisms and susceptibility to sudden sensorineural hearing loss: A systematic review. Audiology Neuroetology 24(1): 8-19.

11. Hallahan DP, Kauffman JM, Pullen PC (2018) Exceptional learners: An introduction to special education. London: Pearson, pp. 480.

\section{ISSN: 2574-1241}

\section{DOI: 10.26717/BJSTR.2019.19.003291}

Mohammad Ashori. Biomed J Sci \& Tech Res

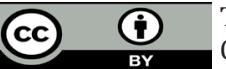

This work is licensed under Creative

Commons Attribution 4.0 License

Submission Link: https://biomedres.us/submit-manuscript.php
12. Behroz-Sarcheshmeh S, Karimi M, Mahmoudi F, Shaghaghi P, JalilAbkenar SS (2017) Effect of training of life skills on social skills of high school students with intellectual disabilities. Journal of Practice in Clinical Psychology 5(3): 177-186.

13. Matson JL, Raymond KL (2010) Social skills in the hearing impaired. Journal of Clinical Child Psychology 18(3): 247-258.

14. Clark McKown (2019) Challenges and opportunities in the applied assessment of student social and emotional learning. Educational Psychologist p. 1-17.

15. Georgina Batten, Peter M Oakes, Tim Alexander (2014) Factors associated with social interactions between deaf children and their hearing peers: A systematic literature review. The Journal of Deaf Studies and Deaf Education 19(3): 285-302.

16. Zaidman-Zait A, Most T, Tarrasch R, Haddad-eid E, Brand D (2016) The Impact of childhood hearing loss on the family: Mothers' and fathers' stress and coping resources. Journal Deaf Study Deaf Education 21(1): 23-33.

17. Turner NE, Mc Donald J, Somerset M (2008) Life skills, mathematical reasoning and critical thinking: A curriculum for the prevention of problem gambling. Journal of Gambling Studies 24(3): 169-181.

18. Korinek L, Popp A (2004) Collaborative mainstream integration of social skills with academic instruction. Journal of Preventing School Failure 41(4): 148-160.

19. Mahvashevernosfaderani A, Adibsereshki, Movallali G (2012) The effectiveness of life skills training on the social skills of hearing-impaired secondary school students in inclusive schools. Journal of Research on Rehabilitation Science. 8(3): 477-488.

20. Kazemi R, Momeni S, Kiamarsi A (2011) The effectiveness of life skills training on the social competence of students with dyscalculia. Journal of Learning Disabilities 1(1): 94-108.

21. Gresham FM, Elliot SN (1990) Social skills rating system manual. Circle Pines, MN: American Guidance Service, pp. 216.

22. Shahim S (1999) Correlations between parents and teachers' ratings of social skills for a group of developmentally disabled children in Iran. Psychological Reports. 85: 863-866.

23. Lawrence BJ, Jayakody D, Henshaw H, Ferguson MA, Eikelboom RH, et al. (2018) Auditory and cognitive training for cognition in adults with hearing loss: A systematic review and meta-analysis. Trends in hearing 22: $1-13$.

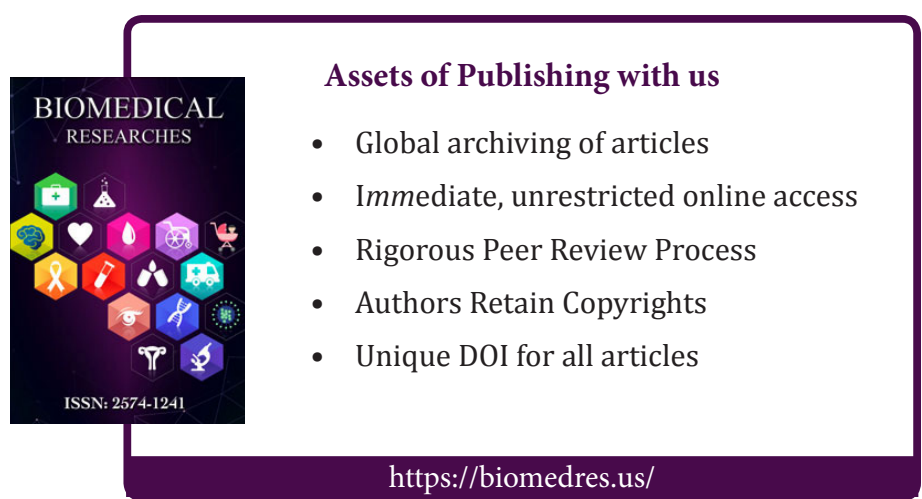

